\title{
Knowledge of computer ergonomics and incidence of musculoskeletal disorders among students of Punjab Agricultural University, Ludhiana, India
}

\author{
Deepika Bisht* and Rupa Bakhshi \\ Department of Family Resource Management, Punjab Agricultural University, Ludhiana (Punjab), INDIA \\ *Corresponding author. E-mail: deepshelly@gmail.com \\ Received: September 11, 2017; Revised received: November 6, 2017; Accepted: February 6, 2018
}

\begin{abstract}
Each year, thousands of individuals are diagnosed with an illness directly related to poorly designed workstations, and among these are Musculoskeletal Disorders (MSDs). MSDs are the repeated trauma and deterioration of the tissues, joint, tendons, and nerves that affect the muscles and supporting structures of the body, caused by the work nature or by an employee's working environment (Bernard 1997). The prevalence of Work-related Musculoskeletal Disorders (WMSD's) is increasing among Computer users throughout the world. Approximately $76 \%$ of Computer professionals from India reported musculoskeletal discomfort in various epidemiological studies. So, the present study was undertaken to study computer/laptop use pattern and knowledge of related ergonomic practices among students of Punjab Agricultural University (PAU), Ludhiana, India and to assess the prevalence and magnitude of computer/laptop use related MSDs among students. 120 students pursuing post-graduation were selected randomly from the four different disciplines namely College of Agriculture, College of Agriculture Engineering and Technology, College of Basic Sciences and Humanities and College of Home Science of PAU. Results revealed that majority of the respondents were in the age group of 26-27 years. They were using computer/laptop for 3-4 years, for 3-4 hours daily and they used to sit in bed while working on computer/laptop. Majority of the respondents had some knowledge about the importance of work behavior while using computer/laptop. Most of the total respondents felt pain in the neck $(88.32 \%)$, lower back $(75.00 \%)$, mid back $(73.33 \%)$ and upper back $(72.50 \%)$ while working on computer/laptop. Overall bodily fatigue or tiredness, shoulder or back pain/stiffness and headache during or after working on the computer were the major symptoms as reported by respondents.
\end{abstract}

Keywords: Body pain, Body posture, Computer, Ergonomics, Musculoskeletal disorders

\section{INTRODUCTION}

Computers are an integral part of life and no longer need specialized training for use. In every sphere of life, the dependence on computers is ever increasing, and this widespread use has led to some important "user" health concerns. Each year, thousands of individuals are diagnosed with an illness directly related to poorly designed workstations, and among these are Musculoskeletal Disorders (MSDs). MSDs are the repeated trauma and deterioration of the tissues, joint, tendons, and nerves that affect the muscles and supporting structures of the body, caused by the work nature or by an employee's working environment (Bernard 1997).The body parts affected are the arms, hands, fingers, neck, back, wrists, legs, and shoulders; and early warning signs include muscle cramping, stiffness, aching, pain, and weakness in an area.The risks include both improper workstation design and faulty posture as prolonged sitting for extended periods leads to poor circulation, the stiffness of joints and pain. Extended hours of continuous work can increase the chance of developing an injury and repetitive strain injuries that develop over time may lead to long-term disability (Karsh et al., 2001). Long-term usage of computers, working at a desk and sitting for a long time in a chair in workplaces are the main reasons playing a role in the musculoskeletal system disorders of office workers. Office workers are forming a very important part of the risk group for musculoskeletal system disorders as they are spending long working hours in front of a computer (Ardahan and Simsek., 2016).

The prevalence of work-related musculoskeletal disorders (WMSD‘s) is increasing among computer users throughout the world (Luis et al., 2003; Arun, 2013) and increase in the frequency of symptoms through the years has been observed with the rapid development of computer technologies and ever-increasing usage of computers (Ulusam et al., 2015 and Piranveyseh, 2016) . The Information Technology (IT) Industry boom in India, since the last two decades, has led to an increased use of computer devices and peripherals. Approximately $76 \%$ of Computer professionals from India reported musculoskeletal discomfort in various epidemiological studies (Talwar et al., 2009; Bhanderi 
et al., 2007; Sharma et al., 2006, Bakhtiar et al., 2003). Padma et al. (2015) in a study on information technology employees also found that around $56 \%$ had musculoskeletal symptoms, 54\% had depression, anxiety, insomnia and $22 \%$ had newly diagnosed hypertension. In the absence of a good ergonomic design, extended work for prolonged periods can adversely affect vision, muscles of the neck, upper back, shoulders and arms, leading to visual and muscular fatigue and discomfort (musculoskeletal condition). Globally, the number of people suffering from musculoskeletal conditions has increased by 25 percent over the past decade, and these conditions make up $2 \%$ of the global disease burden (Connelly et al. 2006). According to Britain Labour Force Survey (2015), a total of 9.5 million work days were lost as a result of the WMSD cases, which is a loss of 17 days per person. It was determined that $40 \%$ of the cases that resulted in a work-related time loss comprised of WMSDs (Health and Safety Executives., 2015). It is proved in several studies that ergonomic modifications can decrease the frequency of musculoskeletal pain or discomfort, but some of these modifications are costly and difficult to recommend in many workplaces especially in developing countries (Mehrparvar et al., 2014). Mehrparvar et al. (2014) compared the effect of ergonomic modifications and workplace exercises in reducing the frequency of musculoskeletal pain and discomfort in a group of office workers and found that both interventions significantly reduced complaints in a similar manner except for low back pain which was reduced in exercise group more than the other group. Mirmohammadi et al. (2012) in their study also found a beneficial effect of training in the reduction of awkward postures. So, the present study was planned to study computer/laptop use pattern and knowledge of related ergonomic practices among students of PAU and to assess the prevalence and magnitude of computer/laptop use related MSDs among them.

\section{MATERIALS AND METHODS}

In order to meet the objectives of the study, a survey of students was considered appropriate using a structured questionnaire to gather quantitative data. The questionnaire contained questions related to background information of the respondents, their computer use pattern, knowledge about computer ergonomics and health problems due to computer use. The study used a sample of 120 students pursuing post-graduation from within four different disciplines, namely College of Agriculture, College of Agriculture Engineering and Technology, College of Basic Sciences and Humanities and College of Home Science, of Punjab Agricultural University, Ludhiana, Punjab, India. The sample was selected using the random method, and data collection was done from June to August 2016.

Body map (Corlett and Bishop, 1976): Pain experienced by respondents in different body parts were measured with the help of suitable body map technique
Assigned score values for pain experienced by respondents in different parts of the body

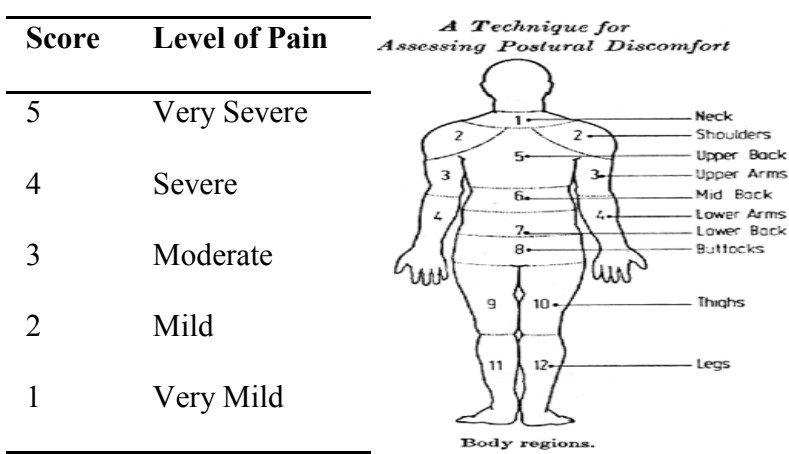

Simple averages, percentages and mean score were applied to analyze the data.

and to ascertain the degree of severity of pain, a five point scale (Verghese et al., 1996) was used as given below:

\section{RESULTS AND DISCUSSION}

Table 1 shows that mean age of female respondents was 25.87 years and that of male respondents was 26.17 years. Majority of the respondents, $51.67 \%$ girls and $45 \%$ boys were using computer/laptop for 3-4 years. About $88.33 \%$ of the girls and $75 \%$ boys were using computer/laptop daily and on average girls spent 4.20 hours per day working on computer whereas boys

Table 1. Background information of respondents.

\begin{tabular}{|c|c|c|c|}
\hline & Girls & Boys & Total \\
\hline \multicolumn{4}{|l|}{ Age (Years) } \\
\hline $24-25$ & $23(38.33)$ & $21(35.00)$ & $44(36.67)$ \\
\hline $26-27$ & $28(46.67)$ & $27(45.00)$ & $55(45.83)$ \\
\hline $28-29$ & $7(11.67)$ & $9(15.00)$ & $16(13.33)$ \\
\hline $30-31$ & $1(1.67)$ & $3(5.00)$ & $4(3.33)$ \\
\hline $34-35$ & $1(1.67)$ & $0(0.00)$ & $1(0.83)$ \\
\hline \multicolumn{4}{|c|}{ Total period of computer/laptop use (Years) } \\
\hline $3-4$ & $31(51.67)$ & $27(45.00)$ & $58(48.33)$ \\
\hline $5-6$ & $14(23.33)$ & $15(25.00)$ & $29(24.17)$ \\
\hline $7-8$ & $8(13.33)$ & $8(13.33)$ & $16(13.33)$ \\
\hline $9-10$ & $2(3.33)$ & $6(10.00)$ & $8(6.67)$ \\
\hline $11-12$ & $5(8.33)$ & $4(6.67)$ & $9(7.50)$ \\
\hline \multicolumn{4}{|c|}{ Weekly computer use } \\
\hline Thrice & $1(1.67)$ & $9(15.00)$ & $10(8.33)$ \\
\hline Four times & $6(10.00)$ & $6(10.00)$ & $12(10.00)$ \\
\hline Daily & $53(88.33)$ & $45(75.00)$ & $98(81.67)$ \\
\hline \multicolumn{4}{|c|}{ Computer use per day (hours) } \\
\hline $3-4$ & $45(75.00)$ & $53(88.33)$ & $98(81.67)$ \\
\hline $5-6$ & $10(16.67)$ & $5(8.33)$ & $15(12.50)$ \\
\hline $7-8$ & $4(6.67)$ & $0(0.00)$ & $4(3.33)$ \\
\hline $9-10$ & $0(0.00)$ & $1(1.67)$ & $1(0.83)$ \\
\hline $11-12$ & $1(1.67)$ & $1(1.67)$ & $2(1.67)$ \\
\hline \multicolumn{4}{|c|}{ Furniture used while working on computer/laptop } \\
\hline Table and Chair & $17(28.33)$ & $22(36.67)$ & $39(32.50)$ \\
\hline Only chair & $0(0.00)$ & $2(3.33)$ & $2(1.67)$ \\
\hline Bed & $22(36.67)$ & $22(36.67)$ & $44(36.67)$ \\
\hline Bed and Chair & $17(28.33)$ & $21(35.00)$ & $38(31.67)$ \\
\hline Bed and study table & $12(20.00)$ & $2(3.33)$ & $14(11.67)$ \\
\hline
\end{tabular}


Deepika Bisht and Rupa Bakhshi / J. Appl. \& Nat. Sci. 10(1): 323 - 329 (2018)

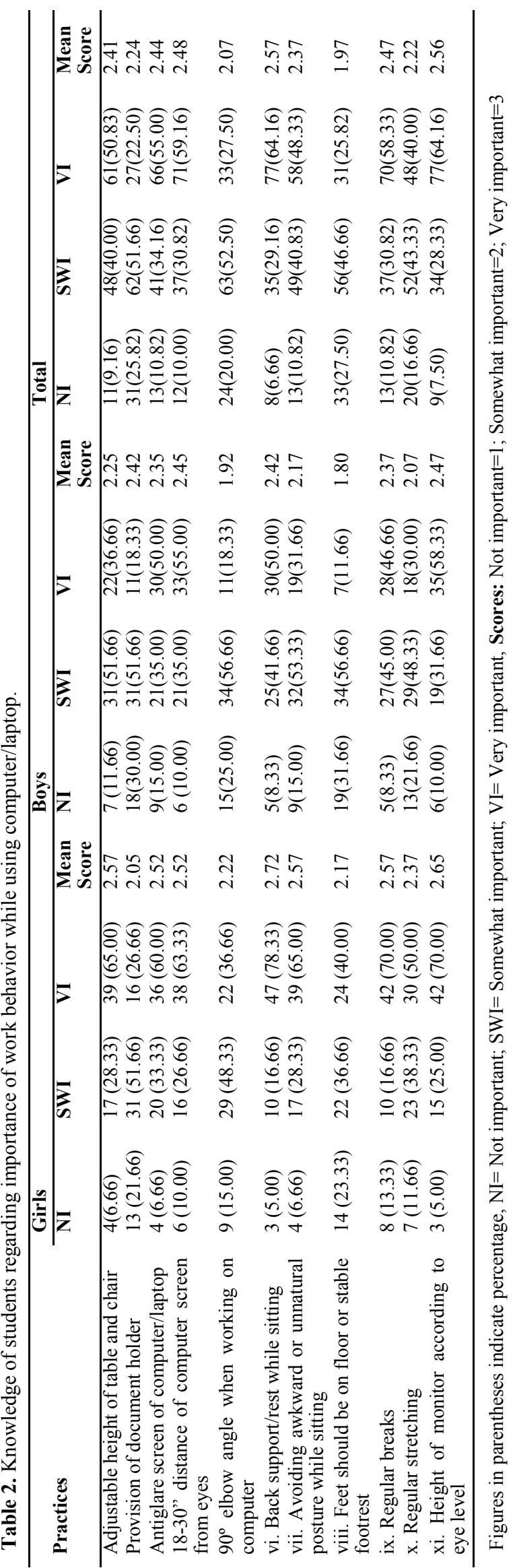

spent 3.57 hours per day. Table 1 also unveils that majority of the total respondents $(36.67 \%)$ were using bed while working on computer/laptop followed by $32.5 \%$ who were using table and chair. Use of bed and chair while working on computer/laptop was done by 31.67 $\%$ respondents, $11.67 \%$ respondents used bed and study table, and only chair was used by $1.67 \%$ of the respondents.

Working at a computer often involves sitting in one position for long hours and requires repetitive motions. So, proper workstation setup, suitable furniture, regular rest breaks and stretching exercises can increase muscle flexibility, reduce the risk of injury, and address muscular imbalances (Chim, 2014). An individual's knowledge base plays a crucial role in the behavioral patterns he or she adopts. Kumah et al. (2016) in a study tested the knowledge of respondents regarding computer ergonomics and found that most $(70 \%)$ of the workers acknowledged not having knowledge of ergonomics related to computer use practices. Shantakumari et al. (2012) in a study also reported that only $44 \%$ students were aware of computer ergonomics. In the present study also students were questioned about their knowledge of work behavior while using computer/laptop and the results (Table 2) reveal that majority $(65 \%)$ of the girls considered adjustable height of table and chair as very important whereas, majority of the boys $(51.66 \%)$ considered it somewhat important. Provision of document holder was perceived somewhat important by the majority $(51.66 \%)$ of girls as well as boys. Working for long hours on the computer can put a strain on eyes of the worker and can cause eye irritation. To reduce these ill-effects of computer use, we can use the antiglare screen on our computer/laptop and should not work with the screen very near to our eyes. Sixty $\%$ of girls and $50 \%$ of boys considered that antiglare screen of computer/laptop is very important. Regarding distance of computer screen from eyes, the majority of both girls and boys considered that a distance of $18-30 "$ is very important. To relieve our arms and back from the stress of continuous work on the computer, arm rests and back support are very important. About $48 \%$ of girls and $56 \%$ of boys considered that an elbow angle of $90^{\circ}$ when working on the computer is somewhat important. The comfortable sitting position, use of backrest inclined for maximum convenience, frequent change in posture, rest or stretches can help in the prevention of low back pain (Khan et al., 2012 ). Back support/rest while sitting was perceived very important by $78.33 \%$ girls and $50 \%$ boys.

Asymmetric postures and unsupported positions can increase the load on the spine. Postural stress can increase the physiological cost and fatigue while performing the task and may also lead to pain and injuries to vertebral column in the long run (Joshi, 2006). Khalil and Rosemoff (1993), in their studies on 
Deepika Bisht and Rupa Bakhshi / J. Appl. \& Nat. Sci. 10(1): 323 - 329 (2018)

Table 3. Mean Scores for frequency of body pain felt while working on computer.

\begin{tabular}{lllllll}
\hline Body parts & Girls & Mean score & Boys & Mean score & Total & Mean score \\
\hline Neck & $53(88.32)$ & 2.10 & $53(88.32)$ & 2.07 & $106(88.32)$ & 2.08 \\
Shoulder joint & $39(65.00)$ & 1.72 & $25(41.67)$ & 1.50 & $64(53.33)$ & 1.61 \\
Upper arms & $32(53.33)$ & 1.52 & $21(35.00)$ & 1.35 & $53(44.17)$ & 1.44 \\
Lower arms & $25(41.67)$ & 1.42 & $14(23.33)$ & 1.27 & $39(32.50)$ & 1.34 \\
Hand/Wrist & $32(53.33)$ & 1.60 & $29(48.33)$ & 1.52 & $61(50.82)$ & 1.56 \\
Upper back & $51(85.00)$ & 2.12 & $36(60.00)$ & 1.77 & $87(72.50)$ & 1.93 \\
Mid back & $45(75.00)$ & 1.92 & $43(71.67)$ & 1.77 & $88(73.33)$ & 1.84 \\
Lower back & $48(80.00)$ & 2.02 & $42(70.00)$ & 1.82 & $90(75.00)$ & 1.92 \\
Knee & $18(30.00)$ & 1.32 & $13(21.67)$ & 1.25 & $31(25.82)$ & 1.28 \\
Buttocks & $45(75.00)$ & 1.92 & $36(60.00)$ & 1.67 & $81(67.50)$ & 1.79 \\
\hline
\end{tabular}

Figures in parentheses indicate percentage, Scores: Never $=1$; Sometimes $=2$; Always $=3$

Table 4. Mean Scores for frequency of bodily symptoms during or after computer/laptop use.

\begin{tabular}{|c|c|c|c|c|c|c|}
\hline Symptoms & Girls & Mean score & Boys & Mean score & Total & Mean score \\
\hline Overall bodily fatigue or tiredness & $58(96.66)$ & 1.51 & $49(81.66)$ & 2.00 & $107(89.16)$ & 1.74 \\
\hline $\begin{array}{l}\text { Neck, shoulder, or back pain/ } \\
\text { stiffness }\end{array}$ & $55(91.66)$ & 2.17 & $51(85.00)$ & 1.92 & $106(88.33)$ & 2.03 \\
\hline $\begin{array}{l}\text { Headaches during or after working } \\
\text { at the computer }\end{array}$ & $54(90.00)$ & 2.15 & $42(70.00)$ & 1.72 & $96(80.00)$ & 1.93 \\
\hline Burning eyes & $45(75.00)$ & 2.00 & $46(76.66)$ & 2.00 & $91(75.83)$ & 2.00 \\
\hline Stress and depression & $37(61.66)$ & 1.72 & $29(48.33)$ & 1.52 & $66(55.00)$ & 1.62 \\
\hline $\begin{array}{l}\text { Distance vision is blurry when look- } \\
\text { ing up from computer }\end{array}$ & $34(56.66)$ & 1.72 & $34(56.66)$ & 1.67 & $68(56.66)$ & 1.68 \\
\hline Blurred vision & $32(53.33)$ & 1.67 & $37(61.66)$ & 1.70 & $69(57.5)$ & 1.67 \\
\hline Discomfort or stiffness in the hands & $27(45.00)$ & 1.50 & $28(46.66)$ & 1.50 & $55(45.83)$ & 1.50 \\
\hline Redness of eyes & $25(41.66)$ & 1.52 & $27(45.00)$ & 1.52 & $52(43.33)$ & 1.52 \\
\hline Double vision & $21(35.00)$ & 1.42 & $16(26.66)$ & 1.30 & $37(30.83)$ & 1.36 \\
\hline Numbness and coldness in the hands & $20(33.33$ & 1.37 & $18(30.00)$ & 1.30 & $38(31.66)$ & 1.32 \\
\hline $\begin{array}{l}\text { Driving/night vision is worse after } \\
\text { computer use }\end{array}$ & $18(30.00)$ & 1.35 & $16(26.66)$ & 1.30 & $34(28.33)$ & 1.31 \\
\hline $\begin{array}{l}\text { Need to massage hands, wrists and } \\
\text { arms }\end{array}$ & $33(55.00)$ & 1.72 & $19(31.66)$ & 1.40 & $52(43.33)$ & 1.56 \\
\hline
\end{tabular}

Figures in parentheses indicate percentage, Score: Never $=1$; Sometimes $=2$; Always $=3$

'Ergonomics in Back pain' also found that poor awkward postures cause fatigue, strain and eventually pain and so should be avoided. Hameed (2013) also revealed that the presence of a computer in the workplace leads to a set of peculiar characteristics of the workstation which require the workers to stay in a static posture for long periods. Back pain usually occurs due to sprains and strains in the back as an outcome of static or an awkward posture. In another study, Elisjistom and Nachemson (1970) also reported that unnatural postures lead to several musculoskeletal problems. Avoiding awkward or unnatural posture while sitting was considered very important by the majority $(65 \%)$ of girls but the majority of boys $(53.33 \%)$ considered this practice somewhat important. When sitting on a chair while doing work, feet should touch the floor or should be on a stable footrest to avoid blood overflow in feet, early onset of fatigue and to work comfortably. The knowledge and application of ergonomics can serve to prevent the onset and progress of musculoskeletal injuries and improve one's health status. The "at-ease posture" requires feet resting comfortably on the floor or on a footrest (Khan et al., 2012). This practice was considered very im- portant by the majority (40\%) of girls and was considered somewhat important by the majority $(56.66 \%)$ of boys.

Prolonged sitting leads to a slackening of the abdominal muscles and curvature of the spine which in return is bad for the organs of digestion and breathing (Grandjean et al., 1981). A study conducted by Ariens et al. (2001) found that sitting at work for more than $95 \%$ of the working time is a risk factor for neck pain. Other studies have suggested that prolonged sitting could be a risk factor for the development of LowBack Pain, so frequent breaks are important to avoid back pain (Corlett, 2006; Pope et al., 2002). In the present study, regular breaks and regular stretching while doing work were considered very important by the majority of girls whereas, the majority of boys considered regular breaks as very important and regular stretching as somewhat important. In a study by Henning et al. (1997), frequent short breaks from computer work reduced musculoskeletal discomfort and other computer-related complaints among adults. Oha et al. (2014) in a study also unveiled that individuals having breaks while working at computers were experiencing less pain, while the individuals are not having breaks 


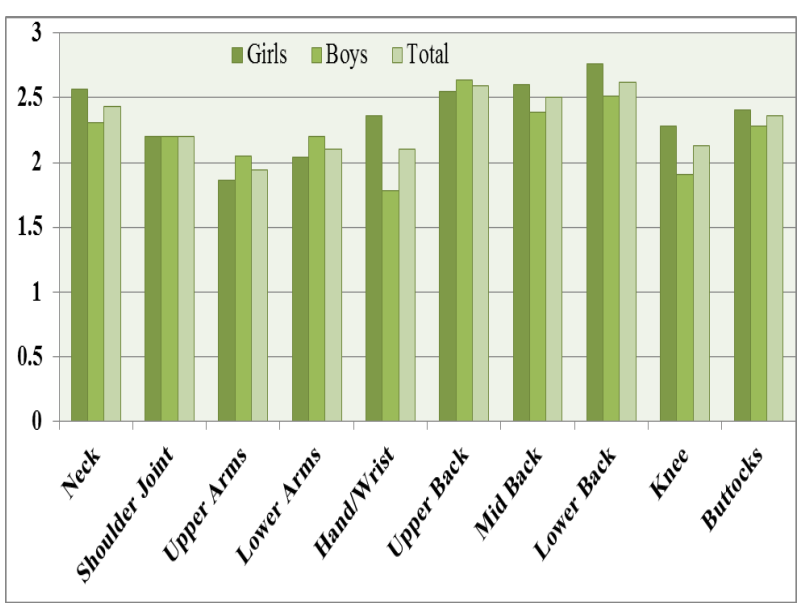

Fig. 1. Mean Scores for intensity of body pain felt while working on computer.

were experiencing more pain (Dutta et al., 2014). Majority of girls $(70 \%)$, as well as boys $(58.33 \%)$, considered that height of monitor should be according to eye level to work comfortably and to minimize eye strain. Among computer users, the most common areas of complaints are the neck, shoulder and back (Glenn, 1995). Gerret et al. (2002) in a study reported that individuals in computer workstations have a prevalence of $10-62 \%$ musculoskeletal symptoms in their neck and shoulder region. Kumah et al. (2016) in another study also reported that $85 \%$ of the respondents experienced musculoskeletal problems in the neck, back and shoulder, which could be attributed to the ergonomic deficiencies at the workstations.

Ardahan and Simsek (2016) in a study on musculoskeletal disorders in computer users reported that participants reported musculoskeletal symptoms most commonly in the neck (67.85\%), upper back $(66.33 \%)$, lower back $(59.49 \%)$, right shoulder $(45.32 \%)$ and left shoulder (43.54\%). Table 3 also reveals the frequency of body pain felt by respondents and results show that majority $(88.32 \%)$ of the girls, as well as boys, felt pain in the neck while working on computer/laptop sometimes as evident from the mean score of 2.10 and 2.07 respectively. Pain in shoulder joint was felt by 65 $\%$ of the girls sometimes (mean score 1.72), and 41.67 $\%$ of the boys felt such pain very rarely (mean score 1.50). About $53 \%$ of girls sometimes (mean score 1.52) felt pain in the upper arms and $35 \%$ boys rarely (mean score 1.35) felt pain in upper arms. In lower arm, $32.50 \%$ of the total respondents rarely felt pain as is evident by the mean score of 1.34 . About $50 \%$ of the total respondents sometimes (mean score 1.56) felt pain in the hand/wrist while working on computer/ laptop. Pain in the upper back was felt by $85 \%$ of girls and $60 \%$ of boys as is evident from the mean score of 2.12 and 1.77 respectively. About $73 \%$ of the total respondents sometimes (mean score 1.84) felt pain in the mid back while working on computer/laptop. Eighty $\%$ of girls and $70 \%$ of boys sometimes (mean

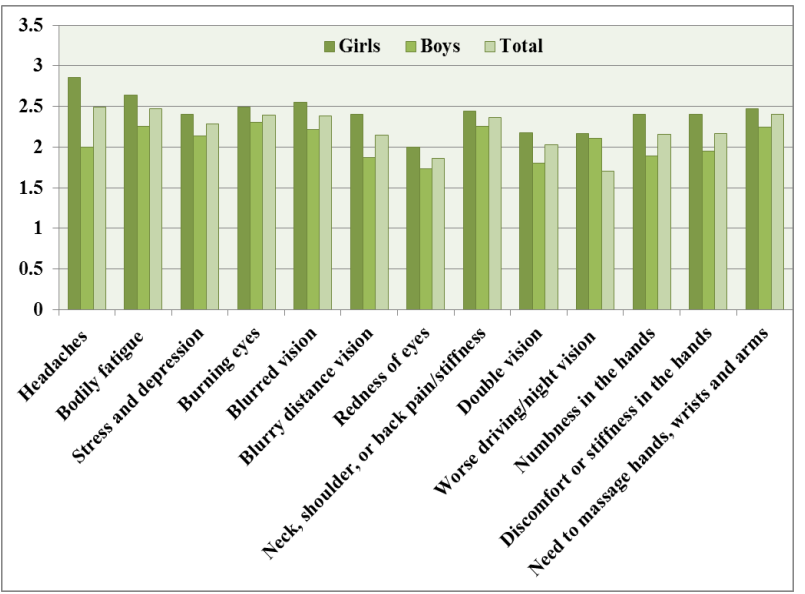

Fig. 2. Mean Scores for intensity of bodily symptoms during or after computer use.

score 2.02 and 1.82 respectively) felt pain in lower back. Pain in the knee while working on computer/ laptop was rarely (mean score 1.28 ) felt by $25.82 \%$ of the total respondents. About $67 \%$ of the total respondents also felt pain in the buttocks though sometimes (mean score $=1.79)$.

Fig. 1 shows the magnitude of pain felt by respondents in different body parts while working on computer/ laptop. The severity of pain was ascertained using a five point scale for which the scores were Very Mild= 1; Mild=2; Moderate=3; Severe=4; Very Severe=5. Results reveal that majority of the total respondents felt mild to moderate pain in the neck, shoulder joints, lower arms, hands/wrists, back, knees and buttocks, whereas the pain felt in upper arms by the majority of the respondents varied from very mild to mild.

Continuous and long term use of computers/laptops can result in a number of health problems. During computer handlingsymptoms like pain, numbness, tingling etc. in various body parts like wrists, shoulders, back and legs and eye strains occur due to improper seating, lack of short breaks during work and improper viewing distance (Khan et al., 2012). Benz (1995) reported that computer-related vision ailments and musculoskeletal disorders affect millions of computer users every year. Table 4 unveils the symptoms which were noticed by the respondents during or after computer/laptop use and their frequency. Results show that majority $(96.66 \%)$ of girls felt overall bodily fatigue or tiredness very rarely (mean score $=1.51$ ), whereas about $81 \%$ of the boys felt these symptoms sometimes (mean score $=2.00)$. About $91 \%$ of the girls and $85 \%$ of the boys sometimes felt pain or stiffness in neck, shoulder or back. Headaches result from several things that occur with computer work like screen glare and poor image quality (Alan, 2000). A headache during or after computer/laptop use was felt by $90 \%$ of girls and $70 \%$ of boys. Burning eyes symptom was reported by $75 \%$ girls and $76.66 \%$ boys. About $61 \%$ girls and $48 \%$ boys also reported 
the problem of stress and depression due to computer/ laptop use. An equal number of girls and boys $(56.66 \%)$ reported blurred distance vision when looking up from the computer. Other symptoms reported by respondents include blurred vision, discomfort or stiffness in the hands, redness of eyes, double vision, numbness and coldness in hands and worse driving/ night vision after computer use. Similar findings were reported in a different study also where all the respondents suffered from one form or another of visual discomfort as a result of prolonged computer usage. Prominent among these discomforts were eyestrain, burning eyes, itchy and red eyes (Kumah et al., 2016). Nearly half of the girls (55\%) and about $31 \%$ of boys needed to massage their hands, wrists and arms during or after computer use.

Stuart (1995) in a study reported that the most common areas of pain complaints among the computer users are the neck and shoulder. Fig. 2 reveals the intensity of bodily symptoms, measured on five point scale (Scores: Very mild $=1$, Mild $=2$, Moderate $=3$, Severe $=4$, Very Severe $=5$ ), reported by respondents due to computer/laptop use. Majority of the total respondents felt mild to moderate a headache, overall bodily fatigue or tiredness, stress and depression, burning eyes, blurred vision, blurred distance vision when looking up from computer, pain or stiffness in neck, shoulder or back, double vision, numbness or coldness in hands, discomfort or stiffness in hands and need to massage hands, wrists and arms. Also very mild to mild redness in eyes and worse driving/ night vision after computer/laptop use was felt by the majority of the total respondents. A national survey by doctors of optometry found that more than $14 \%$ of their patients were present with eye or vision related symptoms resulting from computer work (Sheedy, 1992). The most common symptoms reported were eyestrain, headaches, blurred vision and, neck or shoulder pain.

\section{Conclusion}

Findings of the study confirm that students using computer/laptop are exposed to some ergonomic hazards, which are associated with multiple factors. Majority of the respondents $(88.32 \%)$ felt pain in neck followed by lower back $(75 \%)$, mid back $(73.33 \%)$ and upper back $(72.5 \%)$. About $89 \%$ of the respondents reported overall bodily fatigue or tiredness followed by stiffness or pain in neck, shoulder or back which was experienced by $88.33 \%$ respondents. A headache, stress, irritation and redness of the eye, depression, discomfort and numbness in hands were some of the other problems reported by respondents. So it can be concluded that computer users need to know how to create good ergonomic working arrangements for computer workstations, including placement of the screen, keyboard, mouse and lighting. Furthermore, they need to be aware of the importance of short breaks to decrease the stress in soft tissues, discs and nerves caused by the static postures and prolonged sitting frequently involved in computer use.

\section{REFERENCES}

Alan, Hedge (2000). Big mouse, a solution to Repetitive Strain Injury.New York Times.40: 15-16.

Ardahan, M., and Simsek, H. (2016). Analyzing musculoskeletal system discomforts and risk factors in computerusing office workers. Pak J Med Sci.32(6):1425-1429.

Ariens, G.A., Bongers, P.M. and Douwes, M. (2001). Are Neck Flexion, Neck Rotation, and Sitting at Work Risk Factors for Neck Pain? Results of a Prospective Cohort Study.Occupational Environmental Medicine.58:200207. Retrieved from http://www.ncbi.nlm.nih.gov/pmc/ articles/PMC1740110

Arun Vijay, S. (2013). Work-related Musculo-skeletal Health Problems among the Information Technology Professionals in India: A Prevalence Study. International Journal of Management Research and Business Strategy.2(2):118127.

Bernard, B.P. (1997). Musculoskeletal Disorders and Workplace Factors: A Critical Review of Epidemiologic Evidence for Work-Related Musculoskeletal Disorders of the Neck, Upper Extremity, and Low Back. National Institute for Occupational Safety and Health.Retrieved from http:/www.cdc.gov/niosh/docs/97-141/pdfs/97141.pdf

Benz, L.N. (1995). Carpal Tunnel Syndrome measurement and surveillance management. The comprehensive guide to work injury management, Gaithersburg, Md, Aspen.

Bhanderi, D., Choudhary, S., Parmar, L. and Doshi, V. (2007). Influence of psychosocial workplace factors on occurrence of musculoskeletal discomfort in computer operators. Indian J Community Med.32:225-226.

Bakhtiar, C.S. and Vijaya, R.S. (2003). Attitude Alters the Risk for Development of RSI in Software Professionals. Indian J Occup.Env Med. 7:7 - 10.

Connelly, L.B., Woolf, A. and Brooks, P. (2006).CostEffectiveness of Interventions for

Musculo -skeletal Conditions. "Disease Control Priorities in Developing Countries, 2nd ed. Geneva:World Bank.

Chim, J.M.Y. (2014). Ergonomics for the Prevention of Musculoskeletal Disorders of Computer Users in Hong Kong, Singapore and Japan. $J$ Ergonomics S4: 004. doi:10.4172/2165-7556.S4-004

Corlett, E.N. (2006). Background to sitting at work: research requirements for the design of work seats. Ergon.49:1538 $-46$.

Dutta, N., Koepp, G.A., Stovitz, S.D., Levine, J.A. and Pereira, M.A. (2014). Using sit-stand workstations to decrease sedentary time in office workers: a randomized crossover trial. Int J Environ Res Public Health.11(7):6653-6665.

Elisjistom, C. and Nachemson, A. (1970).Fitting the task to the Man. Applied Ergon.8: 87-88.

Gerret, F., Marcus, M. and Ensor, C. (2002). A Prospective Study of Computer Users: Study Design and Incidence of Musculoskeletal Symptoms and Disorders. American J of Industrial Med.41: 221-235. Retrieved from http:// www.eurooffice.com/download/A\%20prospective\% 20study\%20of\%20computer\%20users\%20I.pdf 
Glenn, B. (1995). "Why working Today can be such a pain". BCS News. Pp 1-4.

Grandjean, Laubi and Hunting (1981). Postural and Visual loads at VDT workplaces. 15: 10-12.

Hameed, P.S. (2013). Prevalence Of Work Related Low Back Pain Among The Information Technology Professionals In India - A Cross Sectional Study. Int $J$ Scientific \& Technology Res. 2(7): 80-85.

Health and Safety Executive. Work-related Musculoskeletal Disorder (WRMSDs) Statistics, Great Britain; 2015 (cited: 2016 January 21). Available from: http:// www.hse.gov.uk/ statistics/causdis/musculoskeletal/ msd.pdf.

Henning, R.A., Jacques, P., Kissel, G.V., Sullivan, A.B. and Alteras-Webb, S.M. (1997). Frequent short rest breaks from computer work: Effects on productivity and wellbeing at two field sites. Ergon.40:78-91.

Joshi, P. (2006). A Study on Biomechanical Problems of Homemakers Relating to Existing Storage Spaces in the Houses. MSc Thesis, Unpublished. Ludhiana:Punjab Agricultural University.

Karsh, B., Moro, F.B.P., Smith, M.J. (2001). The efficacy of workplace ergonomic interventions to control musculoskeletal disorders: A critical examination of the peerreviewed literature. Theoret Issues Ergon Sci.2: 3-96.

Khalil and Rosemoff, H. (1993). Ergonomics in Back pain, a guide to prevention and rehabilitation. Pp 10-12.

Khan, R., Surti, A., Rehman, R. and Ali, U. (2012).Knowledge and practices of ergonomics in computer users.J Pak Med Assoc.62(3):213-17.

Kumah, D.B., Akuffo, K.O., Affram, D.E., Ankamah, E., and Osae, E.A. (2016). Ergonomic Challenges of Employees Using Computers at Work in a Tertiary Institution in Ghana. Optom open access 1: 107.doi:10.4172/2476-2075.1000107.

Luis, O-H., Silvia, T-G., Susana, M-A.and Ignacio, M-R. (2003). Computer use increases the risk of musculoskeletal disorders among newspapers office workers. Arch Med Res. 34(4): 331-42.

Mehrparvar, A.H., Heydari, M., Mirmohammadi, S.J., Mostaghaci, M., Davari, M.H. and Taheri, M. (2014). Ergonomic intervention, workplace exercises and musculoskeletal complaints: a comparative study. Med J Islam Repub Iran. 28:69.

Mirmohammadi, S.J., Mehrparvar, A.H., Olia, M.B. and Mirmohammadi, M. (2012). Effects of training intervention on non-ergonomic positions among video display terminals (VDT) users. Work: A Journal of Prevention, Assessment and Rehabilitation. 42(3): 429-33.

Oha, K., Animagi, L., Paasuke, M., Coggon, D. and Merisalu, E. (2014). Individual and work-related risk factors for musculoskeletal pain: a cross-sectional study among Estonian computer users. BMC Musculoskeletal Disorders. 2014;15:181-185.

Piranveyseh, P., Motamedzade, M., Osatuke, K., Mohammadfam, I., Moghimbeigi, A. and Soltanzadeh, A. (2016). Association between psychosocial, organizational and personal factors and prevalence of musculoskeletal disorders in office workers. Int J Occup Safety Ergon. 22(2):267-273.

Padma, V., Anand, N.N., Swaminatha Gurukul, S.M.G., Syed Mohammed Javid, S.M.A., Prasad, A. and Arun, S. (2015). Health problems and stress in Information Technology and Business Process Outsourcing employees. $J$ Pharm Bioallied Sci. 7(1): 9-13. doi: 10.4103/0975-7406.155764

Pope, M.H., Goh, K.L. and Magnusson, M.L. (2002).Spine ergonomics.Annual Review of Biomedical Engineering.4:49-68.

Shantakumari, N., Eldeeb, R.A., Sreedharan, J. and Gopal, K. (2012). GMJ, $4^{\text {th }}$ Annual Scientific Meeting of Gulf Medical University Poster Proceedings. Pp: 11-14.

Sharma, A., Khera, S., and Khandekar, J. (2006). Computer related health problems among information technology professionals in Delhi. Indian J Community Med.31: 36 -38 .

Sheedy, J.E. (1992). "Vision Problems at video display terminals: A survey of optometrists". J. Am. Optom. Assoc.63(10): 687-692.

Stuart, Carol (1995). "Workplace Ergonomics". Ergonomics Alexandra; 10:1

Talwar, R., Kapoor, R., Puri, K., Bansal, K., and Singh, S. (2009). A Study of Visual and Musculoskeletal Health Disorders among Computer Professionals in NCR Delhi.Indian J Community Med.34: 326 - 328.

Ulusam, S., Kurt, M. and Dülgeroglu, D. (2015). Bilgisayar kullananlarda birikimli travma bozuklukları (Cumulative trauma disorders in computer-users). Mesleki Saglik ve Güvenlik Dergisi (J Turk Occupatinal Health Safety). 2 (6):26-32.

Verghese, M.A., Atreya, N. and Bhatnagar, A. (1996). Ergonomic Studies in India. Tech Bull PG Department ofFamily Resource Management. Mumbai: SNDT Women's University, pp. 26-44. 